\title{
Simplified Analytical Machine Sizing for Surface Mounted Permanent Magnet Machines
}

\author{
Patrick Xie ${ }^{1}$, Ramkumar Ramanathan, Gaurang Vakil, Chris Gerada \\ Power Electronics, Machine and Control Group \\ University of Nottingham \\ Nottingham, UK \\ eexpx1@nottingham.ac.uk ${ }^{1}$
}

\begin{abstract}
This paper proposes a simple analytical machine sizing process for a three-phase surface mounted permanent magnet synchronous machines appropriate for both system level analysis and preliminary machine design. For system-level analysis, the proposed method can generate candidate machine models, be used to check if proposed performance values for a machine in a system level design problem are feasible or be integrated into a system-level optimization considering power electronics, passives, and machine. In machine design, the advantage of analytical process is it quickly generates candidate designs. These designs can be further refined using more computational intensive methods such as FEA, CFD, and machine design software.

Index Terms-Analytical machine sizing, surface mounted permanent magnet synchronous machines, SPMSM
\end{abstract}

\section{INTRODUCTION}

Surface mounted permanent magnet machines have gained popularity due to their high power-to-weight ratio and low power loss, making them suitable for servo and traction applications for industry, transport, domestic items, and aerospace. The main objective in machine design is to meet mechanical operating requirements, typically defined by nominal and peak torque, speed, and duty cycle, for a given operating environment while minimising cost, weight, and losses.

Machine design techniques can be split into analytical and finite element analysis (FEA) techniques with the prior typically being used for preliminary machine design and sizing, and the latter to analyse and refine said preliminary designs. Analytical machine sizing requires less computational effort compared to finite element based techniques and, for that reason, can be integrated into a machine sizing optimisation process or a system level optimisation. If desired, these designs can be later analysed and refined using FEA.

Machine, drive, and system design are typically done separately. An example would by a system designer selecting a machine with fixed parameters in a catalogue/database that delivers the mechanical requirement for the available DC link, from which the inverter, filters and controllers are designed. However, the system designer does not have any influence on the machine's parameters/design. System designers have used simple scaling laws for components and machines [1]. Integrated machine and drive design for weight optimisation has been considered in [2] and [3].

The presented machine sizing procedure gives the system designer the opportunity to optimise the drive as a whole and not just optimise the components of the drive connected to a given machine.

In this paper, an analytical machine sizing procedure is presented. This procedure bridges the gap between system level and machine level design. The optimisation problem defined by the design procedure can be solved using simple iterative methods or more advanced heuristic search methods. [4] used an iterative sizing method that progressively increases the machine dimensions until the desired design targets and specifications are met. [5] investigated population-based optimisation design methods of permanent-magnet synchronous machines using genetic algorithm and particle swarm optimisation. Detailed discussion of these methods is beyond the scope of this paper. The presented design procedure was tested using an iterative method within a user defined search space and resolution.

An outline of the design procedure is presented in section II. The system level machine sizing process is presented in section IV. This is followed by the detailed design in section $\mathrm{V}$ where he air gap and magnets are sized. Next, the thermal modelling is presented in section VI. This full design procedure is used to design three machines of different configurations and power ratings, validated using FEA, and presented in section VII.

For system level designers who don't have prior machine design experience, typical values for various applications are provided to aid preliminary design. For preliminary machine design, this analytical method can be incorporated into computational-efficient design methods.

The following assumptions about the candidate machine designs are made:

- A three-phase, outer stator, inner rotor design is considered.

- Only external cooling, such as natural air convection, forced air convection, and water jacket, is used.

- The permeability of the stator and rotor iron compared to that of the air is considered infinite when determining stator inductance and magnet operating point.

- Magnetic saturation is not considered.

\section{DESIGN PROCEDURE}

The machine sizing process is illustrated in Fig. 1. System level analysis for system level simulations, control loop and filter design is encompassed in steps 1 to 12 from which 
candidate machines mass, volume, efficiency, power factor, stator resistance, stator inductance and magnetic flux linkage are determined. Analysis can be extended from steps 13 to 19 for preliminary machine design sizing.

A quick synopsis of each step is provided as follows. The required machine design inputs are specified in step 1 . The fundamental winding factor $k_{w 1}$ is calculated in step 2. For system level analysis, this step can be skipped and a value of 0.9 can be set for $k_{w 1}$. Approximate rotor sizing (assuming homogeneous rotor in mass calculation), followed by stator sizing using general machine sizing equations are considered in steps 3 to 6 . The windings are dimensioned considering fullpitch or fractional-pitching windings in step 7 from which the stator resistance $R_{s}$ is calculated in step 8. The nominal operating point and voltage limits are considered in the dq current plane from which feasible stator inductance $L_{s}$ and magnetic flux linkage $\lambda_{m}$ are determined in step 9. The power losses and efficiency can be calculated in step 10. All results are filtered and checked if they are within the desired efficiency, power factor and dimensional limits in step 11. The filtered candidate machines' mass are calculated from their known geometry in step 12. At this point, all values appropriate to system level analysis has been determined. For preliminary machine design, the design process is continued. The air gap and magnets are sized for the requested $\lambda_{m}$ and $L_{s}$ in step 14. The demagnetisation current limit at maximum operating temperature is checked to ensure full $\mathrm{dq}$ current range and full field-weakening in step 15. The rotor mass is calculated in step 16 knowing the full dimensions of the magnet and rotor. Candidate designs are filtered again to check they are within dimension and demagnetisation limits in step 17. Given the full dimensions of the machine and calculated machine losses at nominal, a lumped parameter thermal network can be developed from which thermal analysis can be conducted in step 18. Candidate designs are filtered to ensure thermal limits are obeyed. Preliminary machine design has been completed at this point.

The remainder of the document describes in greater detail the steps in the sizing procedure. Recommended values are provided for the system level analysis for simplification. This procedure was executed by the authors in MATLAB though any other programming language can be used.

\section{SPECIFICATIONS}

The design inputs are as follows. These relate to desired machine's performance, its material data, machine geometry and aspect ratios, and operating environment.

- Performance: Continuous operating torque $T_{n o m}$, continuous operating rotor speed $\mathrm{RPM}_{\text {nom }}$, peak torque $T_{p k}$, DC bus voltage $V_{d c}$, peak-to-peak current ripple to peak-topeak phase current ratio $c$, nominal power factor $P F_{n o m}$, and efficiency $\eta_{\text {nom }}$.

- Material data: density $\rho$, conductivity $\sigma$, specific heat capacity $C$, lamination material B-H and $\mathrm{W} / \mathrm{kg}(\mathrm{f})$ curves, and Steinmetz parameters.

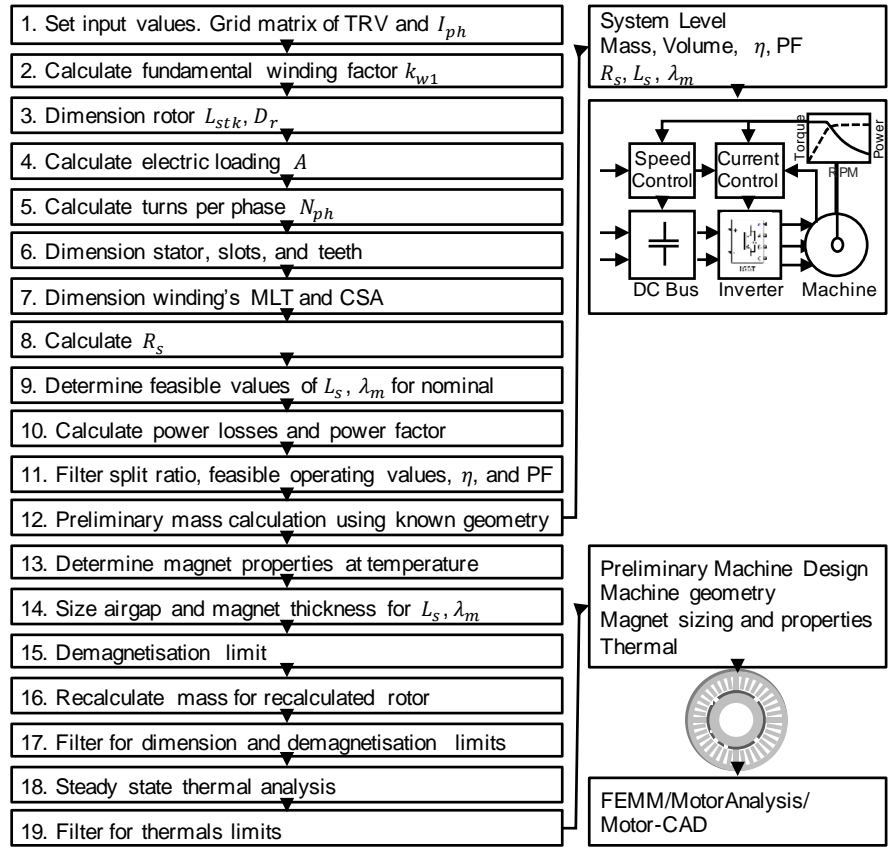

Fig. 1. Sizing flow chart.

- Permanent magnet material properties: remnant reluctance $B_{r}$, intrinsic coercivity $H_{c j}$, relative recoil permeability $\mu_{\text {rec }}$, reversible temperature coefficients for remanence $k_{B_{r}}$ and coercive $k_{H_{c j}}$.

- Machine geometry: magnet width ratio $x_{p m}$, number of slots $N_{s l}$, number of poles $N_{p}$, pitch shortening in number of slots $n_{r}$, rotor diameter to stack length aspect ratio $x$.

- Machine electrical parameters: average flux density across the air gap $B$, current density $J$, inverter switching frequency $f_{s w}$, torque per rotor volume (TRV), slot fill factor $F_{\text {slot }}$.

\section{MACHINE SIZING}

\section{A. Machine dimensioning}

The machine dimensions considered are shown in Fig. 2. Reference [6] provides fundamental electric machine sizing equations (1)-(5). The electric loading $A$ is defined as the average current density around the air gap circumference and expressed as

$$
A=\frac{2 m N_{p h} I_{p h}}{\pi D}
$$

where $m$ is the number of phases, $N_{p h}$ is the number of turns per phase, $I_{p h}$ is the phase current and $D$ is the rotor diameter. The magnet loading $B$ is the average flux density over the rotor surface and is expressed as,

$$
B=\frac{2 p \phi_{1}}{\pi D L_{s t k}}
$$




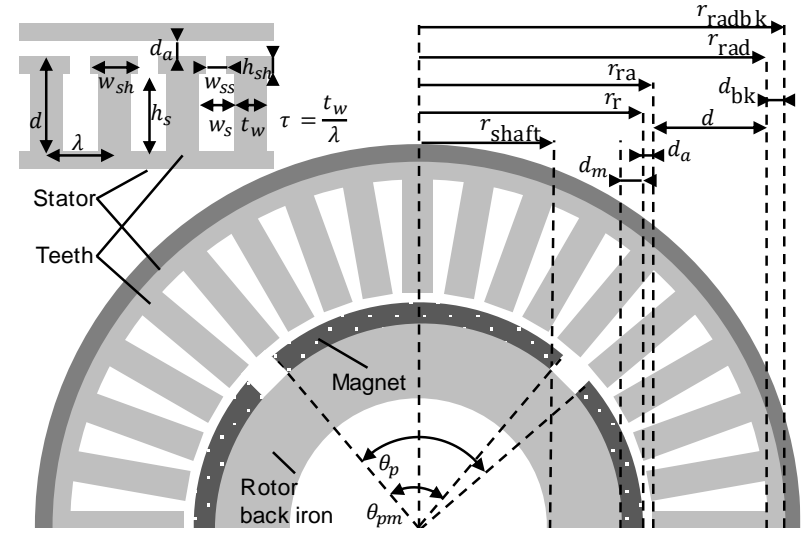

Fig. 2. Machine dimensions.

TABLE I

TYPICAL VALUES OF TRV (CONTINUOUS OPERATION) [6].

\begin{tabular}{lc}
\hline Class of machine & TRV $\left(\mathbf{k N m} / \mathbf{m}^{\mathbf{3}}\right)$ \\
\hline \hline Small totally-enclosed motor (Ferrite magnets) & $7-14$ \\
Totally-enclosed motors (sintered rare earth or NdFeB) & $14-42$ \\
Integral-hp industrial motors & $7-30$ \\
High-performance servomotors & $15-50$ \\
Aerospace machines & $30-75$ \\
\hline
\end{tabular}

where $L_{s t k}$ is the stack length, $\phi_{1}$ is the fundamental component of the air gap flux linkage, and $p$ is the pole pairs. The generated per phase EMF $E$ is expressed as follows,

$$
E=\frac{2 \pi}{\sqrt{2}} k_{w 1} N_{p h} \phi_{1} f
$$

where $f$ is the fundamental electrical frequency, $k_{w 1}$ is the fundamental harmonic winding factor. The torque per rotor volume (TRV) is expressed as shown with respect to $A$ and $B$ for an AC machine, where $V_{r}$ is the rotor volume,

$$
\mathrm{TRV}=\frac{T}{V_{r}}=\frac{\pi}{\sqrt{2}} k_{w 1} A B
$$

Typical values for TRV can be seen in Table I.

The current density $J$ is expressed as follows where $F_{\text {slot }}$ is the slot-fill factor, defined as the ratio of cross-sectional area (CSA) for copper compared to slot, $d$ is the slot depth, and $\tau$ is the ratio of slot tooth width $t_{w}$ to slot pitch $\lambda$,

$$
J=\frac{A}{F_{\text {slot }} d(1-\tau)} \text {. }
$$

TABLE II

TYPICAL CURRENT DENSITIES (CONTINUOUS OPERATION) [6].

\begin{tabular}{lc}
\hline Condition & $\mathbf{J}\left(\mathbf{A} / \mathbf{m m}^{\mathbf{2}}\right)$ \\
\hline \hline Totally-enclosed & $1.5-5$ \\
Air-over, fan-cooled & $5-10$ \\
Liquid cooled & $10-30$
\end{tabular}

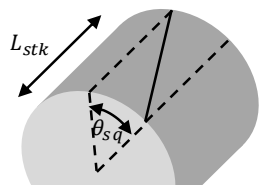

Fig. 3. Skew angle.

Typical values for current densities for available cooling conditions can be found in Table II.

The fundamental winding factor $k_{w 1}$ can be determined as the product of the fundamental pitch factor $k_{p 1}$, the distribution factor $k_{d 1}$, and skew factor $k_{s q 1}$ as shown,

$$
\begin{gathered}
k_{w 1}=k_{p 1} k_{d 1} k_{s q 1}, \\
k_{p 1}=\sin \left(\frac{y_{Q}-n_{r}}{y_{Q}} \frac{\pi}{2}\right), \\
k_{d 1}=\frac{2 \sin \left(\frac{\pi}{2 m}\right)}{\frac{N_{s l} l}{m p} \sin \left(\frac{\pi p}{N_{s l}}\right)}, \\
k_{s q 1}=\frac{\sin \left(\theta_{s q} \frac{\pi}{2}\right)}{\theta_{s q} \frac{\pi}{2}},
\end{gathered}
$$

where $y_{Q}$ is the full pitch slot count equal to $N_{s l} / N_{p}, n_{r}$ is the pitch shortening in number of slots, and $\theta_{s q}$ is the skew angle, as shown in Fig. 3, typically set at one slot such that $\theta_{s q}=2 \pi / N_{s l}$. Typical values for $k_{w 1}$ is $0.85-0.95$ [6] and can be used for system level analysis.

For a given value of TRV and stack length $L_{s t k}=x D$, rotor volume $V_{r}$, and rotor diameter $D$ are calculated. The average magnetic loading $B$ is related to the peak tooth magnetic flux $B_{t(p k)}$ as follows,

$$
B=2 \tau B_{t(p k)} / \pi
$$

Typical values of $B_{t(p k)}$ is $1.6 \mathrm{~T}$ and for $\tau=0.5$, this gives $B \approx 0.5$,

The magnetic loading $A$ can be calculated using (4). $N_{p h}$ can be solved from (1) giving,

$$
N_{p h}=\frac{A \pi D_{r}}{2 m I_{p h}} .
$$

The slot depth $d$ can be determined from (5). Typical value for $F_{\text {slot }}$ is 0.4 [6]. The stator dimensions $r_{r a}, r_{r a d}$, and $r_{r a d b k}$ are determined. An initial estimation of $1 \mathrm{~mm}$ is used for the air gap $d_{a}$ but will be corrected during the preliminary machine design level calculation. The back-iron depth $d_{b k}$ as follows,

$$
d_{b k}=\frac{N_{s l} m}{N_{p}} t_{w} .
$$

The split ratio $S=r_{r} / r_{r a d b k}$ has typical values of $0.55-0.65$ for AC machines. 


\section{B. Windings, conductors, and stator resistance}

To determine the stator resistance $R_{s}$, the per-phase conductor's length and cross sectional area needs to be determined. The total cross-sectional area (CSA) of copper $A_{c u(t o t a l)}$ can be determined from the product of $F_{\text {slot }}$ with the slots CSA $A_{\text {slots }}$,

$$
\begin{gathered}
A_{\text {slots }}=\pi\left(r_{\text {rad }}^{2}-r_{r a}^{2}\right)-N_{s l} d t_{w}, \\
A_{\text {cu }(\text { total })}=F_{\text {slots }} A_{\text {slots }} .
\end{gathered}
$$

The CSA of a single copper conductor $A_{c u(w i r e)}$ is determined,

$$
A_{c u(\text { wire })}=A_{c u(t o t a l)} /\left(6 N_{p h}\right)
$$

The diameter of the conductor in a round wire $d_{c u(w i r e)}$ can determined from this,

$$
d_{c u(\text { wire })}=2 \sqrt{A_{c u(\text { wire })} / \pi} .
$$

The maximum diameter of wire consisting of insulation and conductor assuming square packing pattern $d_{\text {wire }}$ is determined as follows. This value is the minimum value of the slot opening at the stator bore $w_{s s}$.

$$
d_{\text {wire }}=\frac{d_{c u(\text { wire })}}{2} \sqrt{\frac{\pi}{F_{\text {slot }}}}
$$

Total length of wire for each phase $l_{p h}$ is determined as follows where $l_{\text {end }}$ is the per turn mean end winding length for semicircular end winding path and $n_{r}$ is the pitch shortening in number of slots [7],

$$
\begin{gathered}
l_{p h}=N_{p h}\left(l_{\text {end }}+2 L_{s t k}\right), \\
l_{\text {end }}=\left(\frac{\pi^{2}}{2 N_{s l}}\right)\left(1-\frac{n_{r} N_{p}}{N_{s} l}\right)\left(r_{r a}+r_{r a d}\right) .
\end{gathered}
$$

The stator resistance $R_{s}$ can now be determined knowing the conductors total length and wire copper cross-sectional area,

$$
R_{s}=\frac{l_{p h}}{\sigma_{c u} A_{c u}(\text { wire })},
$$

where $\sigma_{c u}$ is the copper electrical conductivity.

\section{Operating point, stator inductance, and magnetic flux linkage}

The steady state dq voltage equations in the synchronous reference frame for a three-phase non-salient pole SPMSM are as follows where $i_{d}$ and $i_{q}$ are the d- and q- axis currents, $v_{d}$ and $v_{q}$ are the d- and q- voltages, $\lambda_{d}$ and $\lambda_{q}$ are the $\mathrm{d}$ - and q- flux linkages, $\lambda_{m}$ is the permanent magnet flux linkage, and $\omega_{e}$ is the electrical frequency. For an SPMSM, it is assumed that d- and q-axis stator inductances are equal such that $L_{s}=$ $L_{d}=L_{q}$.

$$
\begin{gathered}
v_{d}=R_{s} i_{d}-\omega_{e} L_{s} i_{q}, \\
v_{q}=R_{s} i_{q}+\omega_{e} L_{s} i_{d}+\omega_{e} \lambda_{m} . \\
\lambda_{d}=L_{s} i_{d}+\lambda_{m} \\
\lambda_{q}=L_{s} i_{q}
\end{gathered}
$$

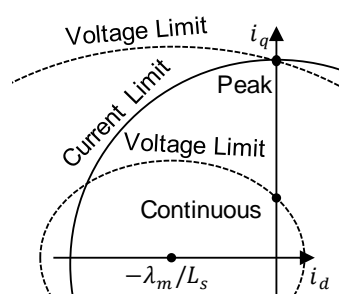

Fig. 4. Continuous and peak operating points on the dq-current plot.

$$
\left|\lambda_{d q}\right|=\sqrt{\lambda_{d}^{2}+\lambda_{q}^{2}}
$$

The relationship between electrical and mechanical angular speed $\omega_{e}$ and $\omega_{m}$ is as follows where $p$ is the pole pairs,

$$
\omega_{e}=\omega_{m} p,
$$

The electromechanical torque equation is as follows,

$$
T_{e m}=\frac{3 p}{2} \lambda_{m} i_{q} .
$$

Voltage and current limits $V_{\max }, I_{\max }$, expressed as follows, need to be considered during operation,

$$
\begin{gathered}
V_{\text {max }}=\frac{V_{d c}}{\sqrt{3}} \geq \sqrt{v_{d}^{2}+v_{q}^{2}} \\
I_{\text {max }}=\frac{2 T_{p k}}{3 p \lambda_{m}} \geq \sqrt{i_{d}^{2}+i_{q}^{2}} .
\end{gathered}
$$

The considered continuous and peak torque operating points are shown in Fig. 4. Portions of the voltage limit ellipses crossing the continuous and peak operating points are shown by the dashed lines and a portion of the current limit circle is represented by the solid line arc. For these operating points, no field-weakening is present, thus $i_{d}=0$. Both operating conditions are at the voltage limit at their different respective continuous and peak operating speeds.

If $L_{s}, \lambda_{m}$, and $i_{q}$ are known, these values can be substituted into (21), (22), and (28) to check if the voltage limit is respected for an operating electrical angular speed $\omega_{e}$ and respective mechanical angular speed $\omega_{m} . R_{s}$ has been determined during the winding, conductor, and resistance calculations for a given TRV, and winding configuration. $L_{s}$ and $\lambda_{m}$ are determined as follows.

To determine a suitable value of $L_{s}$ for desired current ripple $c$, the PWM waveform is approximated to a square wave with duty cycle of 0.5 and peak-to-peak amplitude of $V_{d c}$. The first harmonic of the square wave is represented as sin-wave of amplitude $(4 / \pi) V_{d c}$ at switching frequency $f_{s w}$. For a desired peak to peak current ripple $\Delta I$ at steady state condition, a value $c$ can be determined as $c=\Delta I /\left(2 i_{q}\right)$ as shown. Stator inductance $L_{s}$ can be determined as follows,

$$
L_{s}=\frac{V_{d c}}{\sqrt{2} \pi^{2} c i_{q} f_{s w}} .
$$


TABLE III

MATERIAL DENSITIES.

\begin{tabular}{lc}
\hline Component & Density $\left(\mathbf{k g} / \mathbf{m}^{\mathbf{3}}\right)$ \\
\hline \hline Steel laminations & 8120 \\
Copper conductor & 8930 \\
Aluminium case & 2810 \\
Insulation & 1750 \\
Magnet (NdFeB) & 7500 \\
Magnet (SmCo) & 8300 \\
Shaft & 7800 \\
\hline
\end{tabular}

Equation (27) can be solved for $\lambda_{m}$ to get an expression with respect to $i_{q}$ and $T_{e m}$,

$$
\lambda_{m}=\frac{2 T_{e m}}{3 p i_{q}} .
$$

Equations (30) and (31) are substituted into (21) and (22) for $i_{d}=0$, and then into voltage limit equation (28) as a function of $i_{q}$ to give,

$$
\left|v_{d q}\right|=\sqrt{\left(-\omega_{e} \frac{V_{d c} T_{s w}}{\pi^{2} c i_{q}}\right)^{2}+\left(R_{s} i_{q}+\omega_{e} \frac{2 T_{e m}}{3 p i_{q}}\right)^{2}} .
$$

The operating electrical angular speed $\omega_{e}$ at the voltage limit for given current operating point $i_{q}$ for $i_{d}=0$ can be determined using the following equation,

$$
\begin{aligned}
& \omega_{e}= \\
& \frac{\sqrt{\left(V_{\text {max }}^{2}-\left|i_{d q}\right|^{2} R_{s}^{2}\right)\left|\lambda_{d q}\right|^{2}+i_{q}^{2} R_{s}^{2} \lambda_{m}^{2}}-i_{q} R_{s} \lambda_{m}}{\left|\lambda_{d q}\right|^{2}} .
\end{aligned}
$$

This equation can be used to determine the maximum operating electrical angular speed at peak torque, where $i_{q}=$ $2 T_{p k} /\left(3 p \lambda_{m}\right)$ assuming no saturation.

\section{Power Loss, Efficiency, Mass}

Copper losses $P_{c u}$ can be calculated from $R_{s}$ and nominal current $I_{p h}$ as follows,

$$
P_{c u}=3 I_{p h}^{2} R_{s} .
$$

Power factor $(\mathrm{PF})$ for the nominal and peak operating point are calculated from their respective operating dq voltages and currents,

$$
P F=\cos \left(\arctan \left(v_{q} / v_{d}\right)-\arctan \left(i_{q} / i_{d}\right)\right) .
$$

Knowing the machines components' dimensions, lengths and CSA's, the components' volume and mass can be determined using their respective densities. Typical material densities can be seen in Table III.

For system level analysis, rotor mass can be approximately calculated by assuming magnet density is the same as back iron density. Magnet and air gap dimensions are fully determined in the air gap and magnet sizing section.

\section{E. System level candidate design selection}

For an array of values for $i_{q}=\sqrt{2} I_{p h}$, corresponding values of $R_{s},\left|v_{d q}\right|, L_{s}$, and $\lambda_{m}$ can be calculated at a chosen operating electrical angular speed $\omega_{e}$. This can be done using a script with (1)-(32). Feasible values of $L_{s}, \lambda_{m}$, and candidate machine designs correspond to values of $\left|v_{d q}\right| \leq V_{\max }$.

Knowing the approximate stator and rotor geometry, their respective mass, losses, efficiency and power factor can be calculated. All designs are checked to see if they match desired design constraints and filtered accordingly. At this stage of the design process, system level design has been completed.

\section{AIR GAP AND MAGNET SIZING}

In this section, the air gap distance $d_{a}$ and the magnet thickness $d_{m}$ are determined considering desired stator inductance $L_{s}$ and magnetic flux linkage $\lambda_{m}$.

\section{A. Inductance}

The fundamental component of the stator inductance for a three-phase SPMSM $L_{s 1}$ is as follows [8], where $g_{2}$ is the effective air gap,

$$
\begin{aligned}
L_{s 1} & =\frac{6}{\pi} \frac{\mu_{0} N_{p h}^{2} k_{w 1}^{2} L_{s t k} r_{r a}}{p^{2} g_{2}} \\
g_{2} & =K_{c} d_{a}+d_{m} / \mu_{r e c}
\end{aligned}
$$

and $K_{c}$ is the Carter's coefficient approximated as follows [8],

$$
K_{c}=\frac{5+w_{s s} / d_{a}}{5+w_{s s} / d_{a}-\left(w_{s s} / d_{a}\right)^{2}\left(d_{a} / \lambda\right)} .
$$

The slot leakage inductance is calculated assuming a rectangular slot shape [8]. The slot permanence per unit length is,

$$
P=\mu_{0}\left(\frac{1}{3} \frac{h_{s}}{w_{s}}+\frac{h_{s h}}{w_{s s}}\right) .
$$

The slots in each phase belt $N_{b}$ and no of coils per turn $N_{c}$ are as follows,

$$
\begin{aligned}
& N_{b}=\frac{N_{s l}}{2 p m}, \\
& N_{c}=\frac{N_{p h}}{2 p N_{b}} .
\end{aligned}
$$

The slot leakage inductance is calculated as follows,

$$
L_{a}=2 p L_{s t k} P N_{c}^{2}\left(4 N_{b}-n_{r}\right) .
$$

The total synchronous inductance $L_{s}$ is the sum of air-gap and leakage inductances,

$$
L_{s}=L_{s 1}+L_{a} .
$$




\section{B. Magnet}

Consider the simplified magnet circuit to represent the opencircuit condition for the magnet in Fig. 5. Subscript "g" refers to the air gap, "L" refers to leakage and " $m$ " refers to magnet. The magnetic area $A_{m}$ is determined as follows, taking the effective area at midway through the magnet,

$$
A_{m}=x_{p m} \frac{\pi}{p}\left(\frac{D}{2}-d_{a}-\frac{d_{m}}{2}\right)
$$

where $x_{p m}=\theta_{p m} / \theta_{p m}$ as shown in Fig. 2. The flux due to the magnet remanence is $\phi_{r}=B_{r} A_{m}$ and self-permanence of the magnet $P_{m 0}$ is determined as,

$$
P_{m 0}=\frac{1}{R_{m 0}}=\frac{\mu_{r e c} \mu_{0} A_{m}}{d_{m}} .
$$

The air gap area $A_{g}$ is calculated as follows where fringing is approximated by adding $d_{a}$ to each of the four boundaries [9],

$$
A_{g}=x_{p m} \frac{\pi}{p}\left(\left(\frac{D}{2}-\frac{d_{a}}{2}\right)+2 d_{a}\right)\left(L_{s t k}+2 d_{a}\right) .
$$

The air gap reluctance $R_{g}$ is $g_{1} /\left(\mu_{0} A_{g}\right)$ where $g_{1}=K_{c} d_{a}$. The leakage factor $f_{l k g}$ is defined as equal to $\phi_{g} / \phi_{m}$. Typical values of $f_{l k g}$ for SPMSM is $0.9-0.95$ [6]. The air gap flux linkage $\phi_{g}$ is determined as follows,

$$
\phi_{g}=\frac{\phi_{r}}{\frac{1}{f_{l k g}}+P_{m 0} R_{g}} .
$$

where $\phi_{r}=B_{r} A_{m}$ and $B_{r}$ is the magnet's remnant reluctance.

From (47), $\phi_{m}$ can be determined using $\phi_{m}=\phi_{g} / f_{l k g}$. The magnet's operating condition can be determined using $B_{m}=\phi_{m} / A_{m}$. Fundamental component of the magnet's flux linkage is determined as follows where $B_{g}=\phi_{g} / A_{g}$ [8],

$$
\lambda_{m 1}=\frac{4}{\pi} \frac{k_{w 1} N_{p h}\left(2 r_{r a}\right) L_{s t k}}{p} B_{g} .
$$

\section{Air gap and magnet length sizing}

The air gap $d_{a}$ and magnet length $d_{m}$ need to be calculated. First, calculate the slot leakage inductance $L_{a}$ using (39)-(42). Then determine the calculate air-gap inductance $L_{s 1}$ using (43).

Equations (37), (38) are substituted into (36) to give an expression of $L_{s 1}$ as a function of $d_{a}$ and $d_{m}$,

$$
\begin{aligned}
& L_{s 1}= \\
& \frac{6 \mu_{0} r_{r a} L_{s t k} N_{p h} 2 \mu_{r e c} k_{w 1}^{2}\left(5 \lambda d_{a}+\lambda w_{s s}-w_{s s}^{2}\right)}{\pi p^{2}\left(\lambda \mu_{r e c}\left(d_{a} w_{s s}+5 d_{a}^{2}\right)+d_{m}\left(5 \lambda d_{a}+\lambda w_{s s}-w_{s s}^{2}\right)\right)} .
\end{aligned}
$$

This can be solved for $d_{m}$ with respect to $L_{s 1}$ and $d_{a}$,

$$
\begin{aligned}
d_{m}= & \frac{6 \mu_{0} r_{r a} L_{s t k} N_{p h}^{2} \mu_{r e c} k_{w 1}^{2}\left(5 \lambda d_{a}-\lambda w_{s s}-w_{s s}^{2}\right)}{\pi p^{2} L_{s 1}\left(5 \lambda d_{a}+\lambda w_{s s}-w_{s s}^{2}\right)} \\
& -\frac{\lambda \mu_{r e c}\left(d_{a} w_{s s}+5 d_{a}^{2}\right)}{5 \lambda d_{a}+\lambda w_{s s}-w_{s s}^{2}} .
\end{aligned}
$$

A function for magnet flux-linkage $\lambda_{m 1}$ with respect to magnet depth $d_{m}$ can be created using (44)-(48). A value of

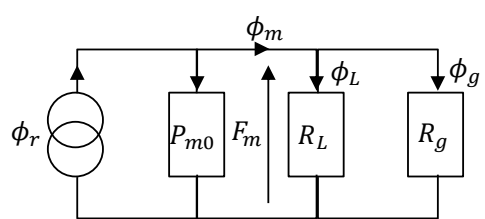

Fig. 5. Magnets open-circuit equivalent reluctance network [9].

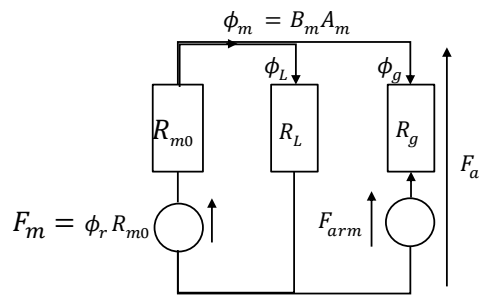

Fig. 6. Demagnetisation equivalent circuit.

$d_{a}$ can be found numerically such that the calculated value of $d_{m}\left(d_{a}, L_{s 1}\right)$ from (50) when substituted into $\lambda_{m 1}\left(d_{m}\right)$ matches the desired magnet flux $\lambda_{m}$.

\section{Demagnetisation limit}

During field-weakening operation, the negative $i_{d}$ current is injected into the machine to reduce the $\lambda_{d}$ and increase the operating range at the voltage limit. However, excess negative $i_{d}$ can demagnetise the magnets. The operating point of the magnet should never go below the knee point of the linear portion of the demagnetisation curve $\left(B_{D}, H_{c J}\right)$ where $H_{c J}$ is the magnet's intrinsic coercive force. This point is temperature dependent with magnets being more sensitive to demagnetisation at higher temperatures. The maximum magnitude of negative $i_{d}$ is determined as follows.

The demagnetisation point $B_{D}$ is determined as follows,

$$
B_{D}=\mu_{r e c} \mu_{0}\left(-H_{c J}\right)+B_{r} .
$$

The magnetic flux $\phi_{m}$ for this operating point is calculated by setting $B_{m}$ as $B_{D}$ such that $\phi_{m}=B_{D} A_{m}$. The equivalent magnetic circuit for this condition is shown in Fig. 6. The armature MMF $F_{a r m}$ for this condition is as follows,

$$
F_{\text {arm }}=\phi_{m} R_{L}-\left(R_{L}+R_{g}\right)\left(\phi_{m}+\left(\phi_{m}-\phi_{r}\right) \frac{R_{m 0}}{R_{L}}\right)
$$

The relationship between the peak current $I_{a r m}$ and the armature MMF is,

$$
I_{\text {arm }}=\frac{p \pi F_{a r m}}{3 k_{w 1} N_{p h}}
$$

Substituting (52) into (53) and solving for $I_{\text {arm }}$ gives the magnitude of the demagnetisation current limit. This value must not be greater than $\lambda_{m} / L_{s}$ such that the full current operating range is reachable. Thus all designs must be checked for their demagnetisation current limit. 


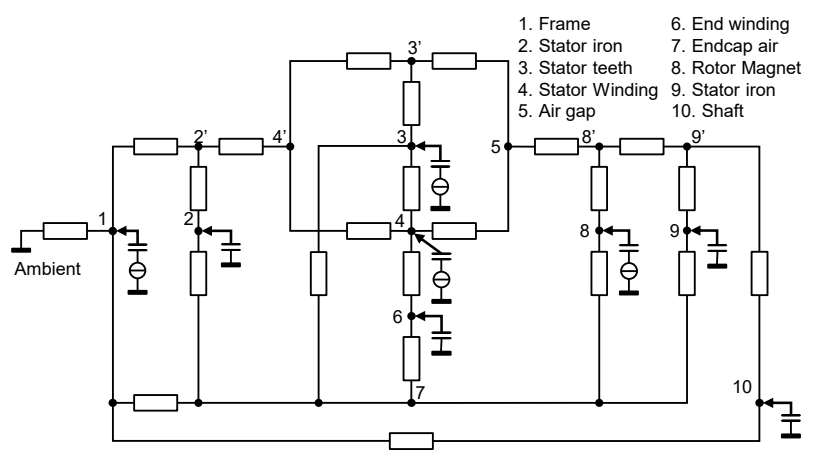

Fig. 7. Lumped parameter thermal network [10].

\section{Thermal Modelling}

\section{A. Lumped parameter thermal network}

The candidate machine's steady state temperatures and transient temperature profiles can be determined using a lumped parameter thermal network (LPTN) [10] as shown in Fig. 7. All machine components are approximated by a general cylindrical shape whereby axial and radial heat flows are assumed to be independent of each other and no circumferential heat flow is present. Given the calculated components' dimensions, masses, and their respective thermal conductivities, the equivalent thermal network for each component can be generated. [11] provides a MATLAB script to calculate the components' temperature for machine losses using the LPTN presented by [10].

\section{B. Frame to ambient thermal resistance}

Frame to ambient thermal resistance as a function of frame and ambient temperature is needed to accurately determine both transient and steady state machine temperatures [12]. The equivalent frame to ambient thermal resistance for natural free convection and radiation cooling calculation procedure is presented in [13] where the machine is approximated as a horizontal isothermal cylinder.

\section{RESULTS}

The design and specifications of three machines sized by the presented design procedure are shown in Table IV. The magnet material is NdFeB 37 and the natural free convection is considered. The TRV and current density search space is selected from Table I and II as $14-42 \mathrm{kNm} / \mathrm{m}^{3}$ and $1.5-10$ $\mathrm{A} / \mathrm{mm}^{2}$ respectively. For a desired mechanical specification and slot/pole configuration, a series of candidate designs were generated as shown for design $\mathrm{A}$ in Fig. 8. It can be seen that as machine size decreases, efficiency reduces as the wire cross-section reduces, leading to increase in stator resistance and ohmic losses increases which in turn leads to increase in nominal winding temperature. The presented machine A of Table IV is labelled in Fig. 8 with arrows.

The designs were validated using 2D electromagnetic solver FEMM [14] and machine design software Motor-CAD. The flux density plots generated from FEMM are shown in Fig. 9.
TABLE IV

MACHINE DESIGNS.

\begin{tabular}{lccc}
\hline Parameter & A & B & C \\
\hline \hline Slots & 12 & 24 & 24 \\
Poles & 4 & 2 & 4 \\
Nominal torque $(\mathrm{Nm})$ & 2 & 5 & 20 \\
Peak torque $(\mathrm{Nm})$ & 3 & 7.5 & 30 \\
Speed $(\mathrm{RPM})$ & 2500 & 5000 & 2500 \\
Mass $(\mathrm{kg})$ & 5.65 & 12.62 & 25.11 \\
Nominal Line Current $\left(\mathrm{A}_{\mathrm{rms}}\right)$ & 4.4 & 22 & 44 \\
Current Density $\left(\mathrm{A} / \mathrm{mm}^{2}\right)$ & 3.9 & 5 & 4.3 \\
TRV $\left(\mathrm{kNm} / \mathrm{m}^{3}\right)$ & 14.6 & 13.4 & 26.8 \\
Stator Resistance $(\Omega)$ & 0.32 & 0.047 & 0.0207 \\
Stator Inductance $(\mathrm{mH})$ & 5.92 & 0.83 & 0.207 \\
Magnet Flux Linkage $(\mathrm{Wb})$ & 0.107 & 0.107 & 0.107 \\
Rotor Diameter $(\mathrm{mm})$ & 47 & 62 & 83 \\
Stator Diameter $(\mathrm{mm})$ & 94 & 124 & 163 \\
Stack Length $(\mathrm{mm})$ & 79 & 103 & 138 \\
\hline
\end{tabular}



Fig. 8.12 slot, 4 pole, 2 Nm, 2500 RPM machine designs, efficiency and temperature vs. mass plot.

Desired values, FEMM- and Motor-CAD- calculated values for torque, and stator inductance are in Table V. Absolute values are accompanied by their respective percentage errors in square brackets,e calculated with respect to the desired values.

\section{CONCLUSION}

A simplified, computationally-efficient sizing procedure for surface mounted permanent magnet synchronous machine has been presented. This procedure is suitable for system and preliminary machine designs. Stator and rotor sizing is

TABLE $\mathrm{V}$

COMPARISON OF DESIRED, FEMM, AND MOTOR-CAD CALCULATED TORQUE AND STATOR INDUCTANCE VALUES.

\begin{tabular}{lccc}
\hline A & Desired & FEMM & Motor-CAD \\
\hline Torque $(\mathrm{Nm})$ & 2.00 & $1.80[-10.0 \%]$ & $1.74[-13.0 \%]$ \\
Stator Inductance $(\mathrm{mH})$ & 5.92 & $5.96[+0.68 \%]$ & $5.64[-4.73 \%]$ \\
\hline B & Desired & FEMM & Motor-CAD \\
\hline Torque $(\mathrm{Nm})$ & 5.00 & $4.22[-15.6 \%]$ & $4.05[-19.0 \%]$ \\
Stator Inductance $(\mathrm{mH})$ & 0.782 & $0.829[+6.01 \%]$ & $0.764[-2.30 \%]$ \\
\hline $\mathbf{C}$ & Desired & FEMM & Motor-CAD \\
\hline Torque $(\mathrm{Nm})$ & 20.00 & $22.97[+14.9 \%]$ & $22.02[+10.1 \%]$ \\
Stator Inductance $(\mathrm{mH})$ & 0.207 & $0.206[+0.88 \%]$ & $0.206[-0.88 \%]$ \\
\hline
\end{tabular}






Fig. 9. Machine flux density plot.

based on fundamental machine sizing equations. A method of calculating the appropriate inductance and magnetic flux linkage for a determined stator resistance, operating speed, available dc voltage link, current ripple and pole count is shown. The magnet and air gap is sized according to desired inductance, magnet flux linkage, operating point of the magnet, and demagnetisation limit. The lumped parameter thermal model is presented with a calculation method for the frame to ambient thermal resistance for natural free convection. The design procedure was verified for different case designs using FEMM, and comparing desired and FEMM calculated torque, inductance, and tooth flux values.

\section{REFERENCES}

[1] A. Diaz Puebla and R. C. Munjulury, "Sizing of actuators for flight control systems and flaps integration in rapid," 2015.

[2] B. Cheong, P. Giangrande, M. Galea, P. Zanchetta, and P. Wheeler, "Integrated motor drive design for weight optimization," in 2017 IEEE Energy Conversion Congress and Exposition (ECCE), Oct 2017, pp. 816-823.

[3] M. Rottach, C. Gerada, and P. W. Wheeler, "Design optimisation of a fault-tolerant pm motor drive for an aerospace actuation application," in 7th IET International Conference on Power Electronics, Machines and Drives (PEMD 2014), April 2014, pp. 1-6.

[4] S. Vaschetto, A. Tenconi, and G. Bramerdorfer, "Sizing procedure of surface mounted pm machines for fast analytical evaluations," in 2017 IEEE International Electric Machines and Drives Conference (IEMDC), May 2017, pp. 1-8.

[5] B. N. Cassimere and S. D. Sudhoff, "Population-based design of surfacemounted permanent-magnet synchronous machines," IEEE Transactions on Energy Conversion, vol. 24, no. 2, pp. 338-346, June 2009.

[6] T. J. E. Miller, Speeds electric motors: an outline of some of the theory in the SPEED software for electric machine design: with problems and solutions. Magna Physics, 2004.

[7] A. Boglietti, A. Cavagnino, and M. Lazzari, "Computational algorithms for induction-motor equivalent circuit parameter determinationpart I: resistances and leakage reactances," IEEE Transactions on Industrial Electronics, vol. 58, no. 9, pp. 3723-3733, Sep. 2011.
[8] J. Kirtley, "6.685 Electric Machines MIT OpenCourseWare," 2013. [Online]. Available: https://ocw.mit.edu/courses/electrical-engineeringand-computer-science/6-685-electric-machines-fall-2013/index.htm

[9] T. J. E. Miller, "Brushless permanent-magnet and reluctance motor drives," 1989.

[10] P. H. Mellor, D. Roberts, and D. R. Turner, "Lumped parameter thermal model for electrical machines of tefc design," IEE Proceedings $B$ Electric Power Applications, vol. 138, no. 5, pp. 205-218, Sep. 1991.

[11] A. R. Prasad and K. P. Rao, "TNM method results compared with finite element analysis for a $30 \mathrm{~kW}$ SCIM motor," International Journal of Engineering Research and Applications, vol. 5, no. 10, pp. 22-31, 2015.

[12] Z. J. Liu, D. Howe, P. H. Mellor, and M. K. Jenkins, "Thermal analysis of permanent magnet machines," in 1993 Sixth International Conference on Electrical Machines and Drives (Conf. Publ. No. 376), Sep. 1993, pp. $359-364$.

[13] F. P. Incropera, A. S. Lavine, T. L. Bergman, and D. P. DeWitt, Fundamentals of heat and mass transfer. Wiley, 2007.

[14] D. Meeker, "Finite element method magnetics," FEMM, vol. 4, p. 32, 2010. 